To the Editors:

\title{
Good postgraduate trainers should be rewarded
}

Plans are underway for the postgraduate medical education (PGME) of Sri Lanka to move from the traditional apprenticeship style to an appraisal based training system. Several speciality Boards of the Postgraduate Institute of Medicine (PGIM) have already

Vol. 49, No. 4, December 2004 formulated necessary changes. Further changes in PGME in the form of quality assurance measures may be introduced in the near future [1]. Quite rightly, standards of training must be upheld and be shown to be upheld. 


\section{Correspondence}

Training is a partnership between the trainer and the trainee. Therefore, the role of a trainer in PGME should not be ignored. The new changes will fail to deliver improvements unless the trainers involved in PGME have confidence and commitment towards the process. Trainers should see it as a constructive opportunity rather than an irrelevant chore. If the changes are to be properly implemented, there must be advantages for the trainers too. Training should not be considered merely as a benign altruistic charity.

The trainers, especially the surgical ones, are under pressure from the two sides-providing service and training. When a trainer is taking a trainee through a procedure, it will almost always take much longer and the service suffers. While laudable and fairly successful attempts are made by surgical trainers to maintain a fair balance between service and training, further increases in commitment on training may make this adjustment increasingly hard to tolerate.

Teaching units with no access to computers, new books, journals and the internet are not appropriate teaching environments. Most of the trainers of the Department of Health do not have office space or secretarial assistance.
Postgraduate trainers have increasingly come to believe that their commitment is taken for granted. Hence, they need to be properly rewarded. This is essential if the postgraduate training is to prosper.

For this certain obstacles must be cleared. Funds should be allocated specifically for training time and supporting training programmes. At the moment this occurs on the cheap, and training largely occurs through the goodwill of the trainers. The PGIM and the Department of Health should acknowledge the educational significance and importance of the trainers. They should receive appropriate recognition and support. For a start, each year one or two good trainers from every speciality can be selected and rewarded with an infrastructure necessary for a good training environment.

This proposal may raise more problems than it solves. Nevertheless, it will at least stimulate a dialogue on the importance of the trainers and on innovative educational initiatives in PGME.

\section{References}

1. Mendis L, Adkoli BV, Adhikari RK, Huq MM, Qureshi AF. Postgraduate medical education in South Asia. British Medical Journal 2004; 328: 779.

AM Abeygunasekera, Urological Surgeon, Teaching Hospital, Karapitiya, Sri Lanka. Tel. +94-11-2763427, e-mail: <amabey@sltnet.lk> (Competing interests: none declared). 